\title{
The Vasopressin V2 Receptor Antagonists: The Vaptans
}

\author{
Michael AB Naafs* \\ Naafs International Health Consultancy, Europe \\ *Corresponding author: Michael AB Naafs, Internist-endocrinologist with a long clinical career in internal medicine and endocrinology, Naafs \\ International Health Consultancy, Europe
}

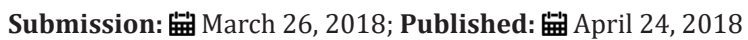

\begin{abstract}
In this mini-review the pathogenesis and pathophysiology of the new vasopressin antagonists are discussed. Indications, appropriate and inappropriate use of the vaptans are evaluated. The efficacy and safety of the vaptans has been well established. Costs are high and the vaptans are not cost-effective in the long-term treatment of autosomal dominant polycystic kidney disease (APDKD) with a cost of U.S. $\$ 744.100$ per equally adjusted life year (QALY) gained compared to standard care. This is seven times the standard willingness to pay treshold. A secondary analysis of the SALT trials reached no significant beneficial cost-benefit analysis for tolvaptan in the treatment of patients with the syndrome of inappropriate secretion of antiduretc hormone (SIADH). U.S. and European expert panels released different treatment guidelines. Solid endpoint studies on the increased mortality of hyponatremia are lacking.
\end{abstract}

\section{Introduction}

Vaptans (aquaretics) are novel V2 receptor antagonists that block vasopressin binding to collecting duct tubular cells of the kidney and increase free water excretion without significantly altering electrolyte excretion. These new therapeutic agents are effective in the treatment of euvolemic and hypervolemic hyponatremia, the commonest electrolyte disorder in inpatients [1-3]. Furthermore, studies consistently find an excess morbidity and mortality in patients with hyponatremia compared to patients with normal plasma sodium concentrations.

The association has been reported in hospitalized patients $[3,4]$, in intensive care units $[5,6]$ and in apparently asymptomatic outpatients with much less severe forms of hyponatremia [7]. The association of hyponatremia with increased mortality maintains in numerous clinical settings including heart failure [8], cirrhosis [9], cancer [10], orthopaedic surgery [11], chronic kidney disease [12] and even in end stage kidney disease $[13,14]$. Guidelines of two expert panels are conflicting [15-17]. Traditional therapeutic approaches as fluid restriction, salt tablets. Loop diuretics and normal saline have been limited efficacious [18,19]. Therefore, the development and availability of new drugs that antagonize the action of vasopressin and the pathogenesis of this disorder, is a most welcome addition to the therapeutic arsenal of hyponatremia. In this mini-review the pathogenesis and pathophysiology of AVP-V2 receptor antagonists are discussed as well as the use of the vaptans in clinical medicine.

\section{Structure, Synthesis and Function of AVP}

Arginine-vasopressin (AVP) and oxytocin (OT) are both neurohypophyseal hormones and share a high sequence and structure homology. Four receptors exist in mammals, three for AVP and a unique receptor for OT, although AVP possesses a nanomolar affinity for all subtypes.AVP is also named the anti-diuretic hormone (ADH) due to its effect on the regulation of water balance. AVP is characterized by the presence of a disulfide bound between Cys1 and Cys6 (cysteine).This results in a peptide constituted of 6 amino-acid cyclic part and a $\mathrm{COOH}$ (carboxy) terminal alphaanimated three residue tail. AVP contains a basic amino-arginine at position 8 and phenylalanine at position 3. The presence of the glycinamide at the $\mathrm{C}$-terminus is absolutely necessary for biological activity of the hormo.

AVP has multiple physiological functions, including body water regulation, control of blood pressure, platelet aggregation and release of coagulation factors, cell proliferation and effects on body temperature, insulin release, memory and social behavior. All these actions are mediated through activation of three specific membranebound receptors present at the surface of the target cells. On the basis of pharmacological and functional studies, these receptors have been classified as V1A, VB and V2 subtypes [19]. There are various V1 and V2 receptors [19-24]. The selective abundance of the AVP-V2 receptor in the kidney determines the actions of AVP 
on a specific organ. Due to the immediate anti-diuresis (increased urinary osmolality, inversely proportional to urine production) observed in response to the administration of specific V2R agonists, such as l-desamino-8-D-AVP (desmopressin), it was previously thought that V2-AVP receptors were exclusively present in the kidneys. Now it has been known that desmopressin in doses 10 30 times higher than used for anti-diuretic purposes increases circulating levels of coagulation factor 8 and von Willebrand factor (vWF) $[25,26]$. The hematological properties of desmopressin gradually changed the idea that V2AVP were exclusively present in the kidney. In patients with X-linked diabetes insipidus, who possess a mutation in the V2R gene (AVPR2), desmopressin failed to cause an increase in circulating vWF [27]. However, in patients with chronic renal failure, V2R agonist stimulation in high doses did raise plasma $v W F$ even after bilateral nephrectomy [25]. These clinical observations strongly supported the existence of extra renal V2Rs. Later studies supported the existence of extra renal V2Rs and positively confirmed V2R effects in the endothelium [28-31].

Tight fluid homeostasis is critical not only at the whole body level but in most organs, tissues and physiolgical systems. Thus, it is not unexpected that the AVP-V2R complex also turns out to play a significant role in local fluid homeostasis, for instance by controlling the elimination and re-absorption of fluid in the inner ear through stimulation of V2Rs to mobilize AQP (aquaporins) water channels, likely in much the same way as occurs in the kidney [32]. The role of V2R in malignancy is less known. Many tumours produce and secrete AVP which has a mitogenic action on cellular growth. V2R is present in a wide panel of human tumour cell lines, including human breast cancer cells, cervical cancer and lung cancer and in corticotrophinomas [33-36]. An antibody-based proteomics showed staining for the AVPR2 gene in 29 of 75 cell types. This staining was most pronounced in the cytoplasm and membranes of the parathyroid. More moderate cytoplasmic staining was seen in the following cell types: the exocrine pancreas, non-keratinized squamous epithelial, smooth muscle, salivary glands, breast and Leydig cells. The physiologic role has to be determined, but other groups could not confirm these findings, possibly raising queries about the specificity of the antibodies used in these experiments [36].

Recently, it has been shown that female rats express significantly more V2R mRNA and protein in kidneys than male rats [37]. In humans the concept of a sex difference in renal sensitivity to desmopressin has been further supported by several studies in adult patients with nocturnia [38]. Autosomal dominant polycystic kidney disease is a ciliopathy characterized by renal cysts and altered fluid and electrolyte transport in the collecting duct. V2mRNAs are elevated compared with healthy subjects and the binding of AVP to V2Rs in the collecting duct increases cAMP and accelerates cyst growth by stimulating cell proliferation and $\mathrm{Cl}-$ dependent fluid secretion [39]. Deficiencies of any part of the renal AVP-V2R-AQP2 axis have profound clinical and pharmacological implications, being responsible for the development of central [40] or nephrogenic diabetes insipidus [41,42].

\section{Use of V2R Antagonists}

SiADH (syndrome of inappropriate antidiuretic hormone secretion) is one of the main indications for VRA use and malignancy is the commonest cause of SIADH [43]. Up to $15 \%$ of patients with SCLC (small cell lung cancer) develop SIADH [44]. Other indications are intracranial disorders, pulmonary disorders, medications, when chronic use is required, idiopathic, hyponatremia from heart failure, non severe hyponatremia and hyponatremia that is not amenable to correction with fluid restriction or other therapies (Table 1).

\section{Table 1}

\begin{tabular}{|c|}
\hline $\begin{array}{c}\text { Hyponatremia from syndrome of inappropriate antidiuretic hormone } \\
\text { secretion }\end{array}$ \\
\hline Intracranial disorders. \\
Pulmonary disorders. \\
\hline Medications, when chronic use is required. \\
\hline Nausea or pain, when chronic and intractable. \\
\hline Idiopathic. \\
\hline Non-severe hyponatremia. \\
\hline Hyponatremia that is not amenable to correction with fluid restriction \\
or other therapies.
\end{tabular}

There is solid evidence supporting the efficacy of VRAs in cancer-associated SIADH. Salahadeen et al. [45] conducted a RCT in which the investigators randomized patients with cancer with non-hypovolemic hyponatremia to either placebo or tolvaptan. Patients in both groups were allowed to "drink to thirst". The primary outcome was $\mathrm{PNa}$ (plasma natrium) correction by day 14 . Secondary outcomes included length of hospital stay and change in Mini-Mental State Examination scores. The data safety monitoring board stopped the study after randomizing 30 patients when the primary endpoint was reached ( $94 \%$ in the tolvaptan group vs. $8 \%$ in the placebo group), which met study stopping for superiority. The secondary endpoints were statistically non-significant between the two groups.

Gralla et al. [46] performed a post hoc analysis of the SALT trials that analyzed 28 hyponatremic patients with SIADH and cancer. The most common causes of cancer were lung (29\%), head and neck (25\%), breast (11\%) and renal cancer (11\%). Patients in the tolvaptan group compared to placebo showed a highly significant improvement in PNa by day 14 ( 5 vs. $-0,3 \mathrm{mmol} / \mathrm{l}$ ) and by day 30 $(6,9$ vs. $1,0 \mathrm{mmol} / \mathrm{l})$ [46]. The efficacy and safety of VRAs in the hyponatremia of heart failure and SIADH has been well established. The SALT- 1 and SALT-2 were two identical RCTs: one in Europe and one in the America's, which enrolled 448 patients with euvolemic and hypervolemic hyponatremia $\mathrm{PNa}<135 \mathrm{mmol} / \mathrm{l}$ to tolvaptan or placebo and followed them for 30 days [47]. SIADH, heart failure and cirrhosis were the most common etiologies. These trials excluded patients with severe hyponatremia (presence of symptoms or $\mathrm{PNa}<120 \mathrm{mmol} / \mathrm{l}$. PNa at days 4 and 30 was significantly higher in the tolvaptan arm. Patients in the tolvaptan group discontinued the drug at the end of the trials and hyponatremia recurred in most 
of them. Adverse events occurred at similar rates in the placebo and the experimental groups in the SALT trials. The majority of adverse events were related to the aquaretic properties of tolvaptan including xerostomia and increased thirst and urination. Overcorrection of hyponatremia occurred only in 1, $8 \%$ of patients in the SALT trials.

The SALTWATER STUDY constituted the follow up of the salt trials enrolling 111 patients and followed them for a median of 1 , 9 years. All patients received tolvaptan that was titrated up to a normal PNa. Fifty-seven percent of patients achieved normal PNa which was maintained during the study. Tolvaptan has been shown to have an overall acceptable safety profile in these two studies. Only six patients in the saltwater study discontinued the study drug due to the aquaretic adverse events of tolvaptan described above [48].

Zeltser et al. [48] randomized 84 patients with euvolemic or hypervolemic hyponatremia with $\mathrm{PNa}$ ranging from 115 to $130 \mathrm{mmol} / \mathrm{l}$ to two different doses of conivaptan $(40$ and $80 \mathrm{mg}$ ) or placebo for 4 days. SIADH and heart failure were the most common causes of hyponatremia in this population [49]. Conivaptan, regardless of the dose, was associated with a significant increase in PNa. No difference in PNa was found between conivaptan doses. The rate of adverse events in both groups was similar. Nevertheless conivaptan was associated with a higher rate incidence of phlebitis and other infusion site reactions especially when the 80mg dose was used. Other adverse events attributed to conivaptan were hypotension and renal dysfunction. None of these led to discontinuation of the drug. Overcorrection of hyponatremia occurred in $7 \%$ of patients on conivaptan in this study.

Five meta-analyses have been published establishing the efficacy of VRAs in the treatment of hyponatremia [50]. Rosen Zvi et al. [51] evaluated 15 studies produced from 1999-2009 assessing the short-term effects of all VRAs combined in the treatment of euvolemic or hypervolemic hyponatremia involving 1125 patients. VRAs were associated with a greater early response rate than controls ( $R R=3,15 ; 95 \% \mathrm{CI}: 2.27-4.37)$ but with significant heterogeneity (I2 (I quadrate) $=55 \%$ ) A risk of rapid PNa correction with a RR of 2, 52 (95\% CI; 2.56-4.41) was found in eight trials. Jaber et al. [52] analyzed 11 RCTs published between 2003 and 2009 examining the success of all VRAs combined in the treatment of euvolemic and hypervolemic hyponatremia involving 1094 patients. VRAs were associated with a significant rise in PNa of 3 ,

\section{Inappropriate Use of Vras}

Table 2: VRA
$3 \mathrm{mmol} / \mathrm{l}$ at day 1 (95\% CI: 2.7-3.8; $\mathrm{p}<0,001)$ without significant heterogeneity (I quadrate $=0 \%, p=0,51$ ). This meta-analysis also found an increase of rapid PNa correction with an OR of 3, 0 $(p<0,001)$ in nine trials [52].

Zhang et al. [53] conducted a meta-analysis of 18 RCTs published between 2003 and 2014 that examined the efficacy of all VRAs in the treatment of euvolemic and hypervolemic hyponatremia appraising 1806 patients Use of VRAs resulted in a significant net increase in PNa of 4, 89mmol/l (95\% CI; 4.45-4.95) in the fixed effects model. The heterogeneity was significant (I quadrate $=67 \%$ ). No publication bias was found in the assessment P Eager=0.45) An increased risk of rapid $\mathrm{PNa}$ correction was also found in 12 studies of this meta-analysis with a RR=2.56 (95\% CI: 1.45-4.53) [53]

Li et al. [54] carried out the analysis of 11 studies published between 2008 and 2016 that examined the efficacy of tolvaptan in the treatment of hyponatremia covering 5209 patients. Nine studies reported the changes in $\mathrm{PNa}$ after tolvaptan therapy and significant heterogeneity was observed across these studies (I quadrate $=76 \%$; $\mathrm{p}<0.001$ ). Therefore, a random effect model was used. The use of tolvaptan was found to be associated with an increase in PNa of 3.99mmol/1 (95\% CI: 2.80-5.19; p<0.001). Publication bias was not found. The use of tolvaptan was also found to be associated with a rapid $\mathrm{PNa}$ correction ( $\mathrm{RR}=8.43$; 95\% CI: 1.06-66.69; $\mathrm{p}=0.04)$ in two trials [54].

Bhandari et al. [55] performed a meta-analysis of 18 trials published between 2013 and 2014 that examined the effectiveness of VRAs in hyponatremia and included a total of 3408 patients in their analysis. The analysis suggests that patients randomized to a VRA (except conivaptan) are significantly more likely to normalize PNa or increase it by more than $5 \mathrm{mmol} / \mathrm{l}$ with tolvaptan having the largest effect ( $R R=3.3$; 95\% CI: 1.97-5.54). However, pooled analysis of tolvaptan trials showed a statistically significant risk of rapid $\mathrm{PNa}$ correction $(\mathrm{RR}=0.85 ; 95 \% \mathrm{CI}$; $1.27-76.35$; $\mathrm{p}=0.03$ ) with uncertain effect size given low numbers of events in each individual trial [55].

The efficacy of tolvaptan is also supported by the analysis of the largest hyponatremia registry to this date with over 3000 patients describing therapeutic practice patterns regarding hyponatremia in the U.S. and Europe $[17,56]$. In this registry, the rise in PNa during the first 24 hours was greater with tolvaptan compared to other traditional therapies. Similar results were observed in the analysis of a registry of cancer patients with euvolemic hyponatremia [57].

\begin{tabular}{|c|}
\hline Contraindicated. \\
\hline Hypovolemia \\
\hline Gastrointestinal losses: vomiting, diarrhea and bleeding \\
\hline Skin losses: burns and excessive sweating \\
\hline Third spacing: acute pancreatitis and small bowe obstruction \\
\hline Renal losses: diuretic use, aldosterone deficiency, cerebral salt wating syndrome and salt wasting \\
\hline
\end{tabular}


nephropathies

Severe hyponatremia (presence of severe symptoms or $\mathrm{PNa}<120 \mathrm{mmol} / \mathrm{l}$

History of hypersensitivity reaction to vasopressin receptor antagonists

Anuria

Impaired thirst mechanism

Concomittant use of drugs that increase plasma levels of vasopressin receptors (i.e CYP3A4

Inhibitors)

Strongly advise against its use

Liver disease

Concomittant use of drugs that increase plasma sodium concentration (e.g. hypertonic saline) Ineffective (low ADH states)

Primary polydipsia

Low solute intake

$\mathrm{GFR}<10 \mathrm{ml} / \mathrm{min}$

Nephrogenic syndrome of inappropriate antidiuresis (NSAID)

Unneccesary (transient high ADH states)

Cortisol deficiency

Thyroid hormone deficiency

Drug-induced syndrome of inappropriate antidiuretic hormone secretion

The use of VRAs is considered inappropriate in a number of settings (Table 2). VRAs are contraindicated in hyponatremia due to hypovolemia as its use may exacerbate hypotension [16]. Hypovolemia can be caused by gastrointestinal losses such as vomiting and diarrhea and bleeding and by skin losses such as excessive sweating and burns. Third spacing in the case of acute pancreatitis and small bowel obstruction also has been reported. Renal losses due to use of diuretics and salt wasting nephropathy are other causes of hypovolemic hyponatremia as aldosterone deficiency and the cerebral wasting syndrome (CSWS) are mentioned. CSWS shares many clinical features of SIADH [58].

Hyponatremia in CSWS appears in the context of intracranial pathology, typically subarachnoid hemorrhage, where either an impaired sympathetic input or an unidentified brain peptide associated with the intracranial disorder causes sodium wasting. As in SIADH, patients with CSWS have also a hypotonic hyponatremia associated with high urine osmolality and high urine sodium but they are actually hypovolemic from sodium wasting. CSWS seems to be a rare entity as most cases of hyponatremia in the context of subarachnoid hemorrhage are either due to SIADH or cortisol deficiency $[59,60]$.

Concerns for liver damage associated with VRAs appeared in the TEMPO 3:4 trial studying the efficacy and safety of tolvaptan to slow down the progression of autosomal dominant polycystic kidney disease (ADPKD) [61]. No elevation of liver function tests was observed in the SALT and SALTWATER trials. It is important to point out that the tolvaptan doses used in the TEMPO 3:4 trials were much higher than the doses commonly used to treat hyponatremia. A post hoc analysis study demonstrated that these events are rare [62]. Nevertheless the FDA issued a drug safety communication restricting the use of tolvaptan to 30 days and avoiding its use in patients with underlying liver disease [63]. Conivaptan a dual V1A/
V2 receptor antagonst effect scan trigger splanchnic vasodilatation and subsequent hypotension, hepatorenal syndrome and variceal bleeding [64].

\section{Vaptans and Screening for ADPKD}

The prevalence of ADPKD is 3 to $4 / 10.000$ in the general population [65]. It is the most common inherited kidney disease. ADPKD is due to gene mutations, mostly in the PKD1 or PKD2 gene [66]. These mutations result in numerous cysts in both kidneys. Seventy percent of patients reach end-stage renal disease (ESRD) at the median age of 58 years [67]. Well known complications are pain, bleeding and infections of the cysts [66]. Renal cysts are accompanied frequently by liver cysts [66]. Renal failure results in cardiovascular problems as hypertension and aneurysms [66].

Until now the treatment consisted of blood pressure control, salt restriction and life style recommendations in the lack of therapeutic options to prevent progressive renal failure [68]. Rigid blood pressure control is not recommended because the rate of renal function decline is not altered, despite a small inhibitory effect on renal cyst growth [69]. Tolvaptan has shown to modulate and inhibit cyst cell proliferation [61]. Tolvaptan delays renal function decline during treatment 5 years long $[61,70]$. This effect is independent of age, severity of renal failure and duration of treatment. Tolvaptan delays renal function decline with $26 \%$ a year. This means 4 years of tolvaptan therapy results in starting dialysis one year later [61]. The most common adverse events are polyuria, thirst and nycturia.

Screening for ADPKD is possible by ultrasound at a very young age [66]. The use of DNA analysis as a screening tool is limited because it is time consuming, expensive and complex. Until now screening for ADPKD was not recommended because a causal therapy was not available. Tolvaptan has changed this 
[61]. Opponents mention the psychological and social burden for a person believed to be healthy [71]. They point to the Insurance consequences of an ADPKD diagnosis. Furthermore an ADPKD diagnosis leads not always to treatment with tolvaptan. Adverse effects can be severe and the costs are high. Urine production can increase to 6-8 litres daily. Only patients with rapidly progressive ADPKD are selected for tolvaptan treatment by established risk profiles [72].

Supporters recommend ADPKD screening for young adult family members of ADPKD patients, especially in the U.S [71]. They also argues that ADPKD screening offers the possibility of IVF (in vitro fertilization) genetic-pre-implantation procedures when one of both partners has ADPKD. Patients with ADPKD have an increased risk of cerebral aneurysms [61]. Therefore a family history of subarachnoid bleedings at young age could be a reason for screening on cerebral aneurysms e.g. once in 5-10 years, starting at the age of 30 [61]. Estrogens and progestagens can increase growth of liver cysts. Oral contraceptives are not recommended for women with ADPKD [68]. In the TEMPO 3:4 study only 8.3\% of patients stopped tolvaptan for reasons of adverse events $[61,70]$. The delay of $26 \%$ in renal function decline yearly with tolvaptan is comparable to ACE (angiotensin converting enzyme) inhibition of the development of diabetic nephropathy [72].

\section{Screening for ADPKD has 3 Possible Results}

1. ADPKD is not present.

2. ADPKD is present but is not of the rapidly progressive type.

3. ADPKD presents in its rapidly progressive manifestation.

This means:

1. Half of screened young adults has no polycystic kidney disease and can be reassured.

2. One quarter has no rapidly progressive ADPKD which is partly reassuring.

3. One quarter has rapidly progressive ADPKD amenable to therapy with V2R antagonists.

It is concluded that the balance favours ADPKD screening in young adult ADPKD family members or at least one screening visit.

\section{Effects of VRAs on Morbidity}

Recent evidence suggests that mild or asymptomatic hyponatremia is associated with increased risk of morbidity outcomes such as neurocognitive deficits and gait abnormalities [7]. The mental component of the SF-12 survey of general health was significantly improved in the combined analysis of both SALT trials and in the SALT- 1 trial but not in the SALT- 2 trial [47]. The insight study was a multicenter randomized double-blind pilot study aimed to investigate the effects of tolvaptan on hyponatremia outcomes in 57 adult patients age 50 and older with chronic and apparently asymptomatic hyponatremia (PNa120-135mmol/l) [73]. The primary endpoint was change neurocognitive composite scores of speed domains (reaction time, psychomotor speed and processing speed\}. Mean base line scores were found to be more than 1 SD lower compared to age matched normal controls. Use of tolvaptan was associated with a statistically significant increase in PNa (from 129 to $136 \mathrm{mEq} / \mathrm{L}$ ) compared to placebo (from 130 to $132 \mathrm{mEq} / \mathrm{L} ; \mathrm{p}<0.001)$.There was no difference in the primary outcome. However, tolvaptan use was associated with a statistically significant improvement of score in the psychomotor speed domain (treatment effect, 0.27; 95\% CI: 0.04-0.51; p=0.03)

\section{Effects of VRAs on Mortality}

The ACTIV in CHF trial randomized 319 hospitalized patients with heart failure ejection fraction of less than $40 \%$ with refractory congestive symptomatology to tolvaptan or placebo. Despite a significant weight loss associated with tolvaptan rates of worsening heart failure were not different than placebo [74]. Post hoc analysis of this trial showed decreased mortality at 60 days associated with improvement of PNa with tolvaptan use [75].

Subsequently, the Everest outcome trial randomized 4133 hospitalized patients with heart failure to tolvaptan or placebo [76]. Primary outcomes were all cause mortality and a combined endpoint of cardiovascular mortality or subsequent hospitalization for worsening heart failure. Only $11.4 \%$ of patients had hyponatremia at baseline in this trial. There were no significant differences in the primary outcomes between groups. A subgroup analysis of this trial showed that tolvaptan was associated with a significant reduction in cardiovascular morbidity and mortality after discharge [77].

\section{Costs of Tolvaptan}

Tolvaptan is used infrequently among patients with heart failure and hyponatremia and is used among sicker patients [78]. The Premier hospital data base was analyzed it assess the utilization of tolvaptan to estimate tolvaptan costs of managing patients with heart failure (HF) and hyponatremia (HN) and the budget impact of tolvaptan use. Tolvaptan was used in $4.96 \%$ of inpatient visits among patients with HF and HN more commonly among sicker patients as reflected in high utilization during intensive care stay (30.46\%). Additionally, utilization increased by length of stay, which can serve as a proxy to disease severity, Tolvaptan costs accounted for $0.3 \%$ of total hospitalization related costs for patients with $\mathrm{HF}$ and $\mathrm{HN}$ and the budget impact was $\$ 52.42$ per visit [78].

Data on the cost effectiveness of tolvaptan are very limited [79]. Erickson et al. [80] developed a decision-analytic model to study the cost effectiveness of tolvaptan for slowing the progression of ADPKD. They compared a case in which patients with ADPKD receive tolvaptan for life, assuming its clinical benefit persists for life until their death, the development of ESRD (end stage renal disease) or liver complications to a case in which these patients received standard care. Measured outcomes included median age 
at onset of ERSD, life expectancy and discontinued quality-adjusted life years (QALYs).Results showed that tolvaptan therapy in 40 yearold men and women with ADPKD with an eGFR of $80 \mathrm{ml}$ ? min//1,73 square meter would prolong the median age of ESRD onset by 6,3 years in women and 6, 8 years in men, increase life expectancy by 2,8 years in women and 2, 3 years in men and yield an increase of 1,2 discontinued QALYs in women and 1, 1 discontinued QALYs in men. This finding suggests a remarkable health benefit if tolvaptan effectiveness can actually be sustained. It would delay RRT (renal replacement therapy) and its high cost, loss of QOL (quality of life) and death associated with ESRD. The benefits would come at a very high cost U.S $\$ 5.760$ per month and U.S. $\$ 744,100$ per QALY gained compared to standard care. This is seven times the standard willingness-to-pay “WTP” treshold, which ranges from U.S. \$50.000U.S. 100.000 per QALY gained [81]. These results clearly showed that tolvaptan is not cost effective.

Dasta et al. [82] performed a study to evaluate the potential costs savings associated with tolvaptan usage in SIADH based on the SALT trials. Use of tolvaptan was associated with a reduced hospital stay and an estimated mean hospital cost reduction of $\$ 694$ per admission in the United States [82].

Cyr et al. [83] conducted a secondary analysis of the SALT trials and showed that hyponatremic patients who received tolvaptan had a hospital stay that was 1, 72 days shorter compared to placebo but this reached not statistical significance [83]. Lee et al. [84] developed a decision-analytic model using the Korean National Health Insurance database to measure the financial impact of tolvaptan compared with placebo in patients with euvolemic and hypovolemic hyponatremia during a 1 month treatment period. The analysis revealed that tolvaptan was more efficacious with less associated costs in patients with marked hyponatremia [84].

Jamokeeah et al. [85] performed a cost-utility analysis using a discrete event simulation to model the progression of patients with hyponatremia who have failed fluid restriction (or were not suitable to fluid restriction) and were therefore treated with tolvaptan or no active treatment through inpatient admissions over a 30 day period in Sweden. Tolvaptan was associated with reduced costs and increased quality-adjusted life years compared with no active treatment strategy [85].

\section{Conclusion}

Vaptans are novel V2 receptor antagonists (VRAs) that are effective in the treatment of euvolemic and hypervolemic hyponatremia. The efficacy and safety of VRAs in the hyponatremia of heart failure and the syndrome of inappropriate anti-diuretic hormone secretion (SIADH) has been well established. Screening for ADPKD (autosomal dominant polycystic kidney disease) of young adult ADPKD family members is favoured in the U.S. but not yet in Europe. Hard data of the impact of VRAs on solid endpoints such as cardiovascular events, hospitalizations and death are lacking. Tolvaptan is not cost effective in the life- long treatment of ADPKD patients with a cost of U.S. $\$ 744.100$ per quality adjusted life-year (QALY) gained compared to standard care. This is seven times the standard willingness-to-pay treshold. More solid end point studies should be performed to ascertain whether the correction of hyponatremia make disappear the increased mortality of this electrolyte disorder.

\section{References}

1. Anderson RJ, Chung HM, Kluge R (1985) Hyponatremia: a prospective analysis of its epidemiology and the pathogenetic role of vasopressin. Ann Int Med 102(2): 164-168.

2. Hoorn EJ, Lindemans J, Zietse R (2006) Development of severe hyponatremia in hospitalized patients: treatment-related risk factors and inadequate management. Nephrol Dial Transplant 21(1): 70-76.

3. Waikar SS, Mount DB, Curhan CG (2009) Mortality after hospitalization with mild, moderate and severe hyponatremia. Am J Med 122(9): 857865.

4. Wald R, Jaber BL, Price LL, Upadhyay A, Madias NE (2010) Impact of hospital-associated hyponatremia on selected outcomes. Arch Int Med 170(3): 294-302.

5. Funk CG, Lindner G, Druml W, Metnitz B, Schwarz C, et al. (2010) Incidence and prognosis of dysnatremias present on ICU admission.Intensive Care Med 36(2): 304-311.

6. Stelfox HT, Ahmed SB, Zygun D, Khandwala F, Laupland K (2010) Characterization of intensive care unit acquired hyponatremia and hypernatremia following cardiac surgery. Can J Anaesth 57(7): 650-658.

7. Rondon Berrios H, Berl T (2015) Mild chronic hyponatremia in the ambulatory setting:significance and management. Clin J Am Soc Nephrol 10(12): 2268-2278.

8. Gheorghiade M, Abraham WT, Albert NM, Gattis Stough W, Greenberg $\mathrm{BH}$, et al. (2007) Relationship between admission serum sodium concentration and clinical outcomes in patients hospitalized for heart failure: an analysis from the OPTIMIZE-HF registry. Eur Heart J 28(8): 980988.

9. Jeng CG, Tsai MH, Tian YC, Chang MY, Lin CY, et al. (2010) Serum sodium predicts prognosis in critically ill cirrhotic patients. J Clin Gastroenterol 44(3): 220-226

10. Doshi SM, Shah P, Lei X, Lahoti A, Salahudeen AK (2012) Hyponatremia in hospitalized cancer patients and its impact on clinical outcomes. Am J Kidney Dis 59(2): 222-228.

11. McCausland FR, Wright J, Waikar SS (2014) Association of serum sodium with morbidity and mortality in hospitalized patients undergoing major orthopedic surgery. J Hosp Med 9(5): 297-302.

12. Kovesdy CP, Lott EH, Lu JL, Malakauskas SM, Ma JZ, et al. (2012) Hyponatremia, hypernatremia and mortality in patients with chronic kidney disease with and without congestive heart failure. Circulation 125(5): 677-684.

13. Nigweker SU, Wenger J, Thadani P, Bhan I (2013) Hyponatremia,mineral metabolism,and mortality in incident maintenance hemodialysis patients: a cohort study. Am J Kidney Dis 62(4): 755-762.

14. Hecking M, Karaboyas A, Saran R, Sen A, Hörl WH, et al. (2012) Predialysis serum sodium level,dialysate sodium and mortality in maintenance hemodialysis patients: the Dialysis Outcomes and Practice Patterns Study (DOPPS). Am J Kidney Dis 59(2): 238-248.

15. Spasovski G, VanHolder R, Allalio B, Annane D, Ball S, et al. (2014) Clinical practice guideline on diagnosis and treatment of hyponatremia. Eur J Endocrinol 170(3): G1-47.

16. Verbalis JG, Goldsmith SR, Greenberg A, Korzelius C, Schrier RW, et al. (2013) Diagnosis, evaluation and treatment of hyponatremia:expert panel recommendations. Am J Med 126(10.Suppl1): S1-42. 
17. Greenberg A, Verbalis JG, Amin AN, Burst VR, Chiodo JA, et al. (2015) Current treatment practice and outcomes. Report of the hyponatremia registry. Kidney Int 88(1): 167-177.

18. Schmale H, Heinsohn S, Richter D (1983) Structural organization of the rat gene for the arginine vasopressin-neurophysin precursor. EMBO 2(5): 763-767.

19. Stephen L, Mouillac B, Bichet D, Michel B, Chini B, et al. (2015) Vasopressin and oxytocin receptors. IUPHAR/BPS Guide to Pharmacolgy.

20. Thibonnier M, Auzan C, Madhun Z, Wilkins P, Berti Mattera L, et al. (1994) Molecular cloning, sequencing and functional expression of a cDNA encoding the human V1A vasopressin receptor. J Biol Chem 269(5): 3304-3310.

21. Naafs Michael AB (2017) Second Messengers in Endocrinology: A Mini-Review of the Cyclic Nucleotides. Endocrinol Metab Int J 5(6): 1-4.

22. Seibold A, Brabet P, Rosenthal W, Birnbaumer M (1992) Structure and chromosomal localization of the human antidiuretic hormone receptor gene. Am J Hum Genet 51(5): 1078-1083.

23. Chiai B, Manning M, Guillan G (2008) Affinity and efficacy of selective ag onists and antagonists for vasopressin and oxytocin receptors: an easy guide to receptor pharmacology. Prog Brain Res 170: 513-517.

24. Chiai B, Mouillac B, Balestre MN, Trumpp Kallmeyer S, Hoflack J, et al. (1996) Two aromatic residues regulate the response of the human oxytocin receptor to the partial agonist arginine vasopressin. FEBS Lett 397: 201-206

25. Mannucci PM, Aberg M, Nilsson IM, Robertson B (1975) Mechanism of plasminogen activator and factor VIII increase after vasoactive drugs. $\mathrm{Br}$ J Haematol 30(1): 81-93.

26. Mannuci PM, Ruggeri ZM, Pareti FI, Capitanio A (1977) 1-Deamino-8-D-arginine vasopressin: a new pharmacological approach to the management of haemophilia and von Willebrands'disease. Lancet 1(8017): 869-872.

27. Bichet DG, Razi M, Lonergan M, Arthus MF, Papukna V, et al. (1988) Hemodynamic and coagulation responses to 1-desamino(8-D-arginine) vasopressin in patients with congenital nephrogenic diabetes insipidus. $\mathrm{N}$ Engl J Med 318(14): 881-887.

28. Forti FL, Armelin HA (2011) Arginine vasopressin controls p27(kip1 protein) expression by PKC activation and irreversibly inhibits the proliferation of K-Ras-dependent mouse Y1 adrenocortical malignant cells. Biochim Biophys Acta 1813(8): 1438-1445.

29. Kauffmann JF, Oksche A, Wollheim CB, Günther G, Rosenthal W, et al. (2000) Vasopressin-induced von Willebrand factor secretion from endothelial cells involves V2 receptors and camp. J Clin Invest 106(1): 107 116.

30. Medina P, Segarra G, Vila JM, Chuan P, Domenech C, et al. (1999) V2-receptor mediated relaxation of human renal arteries in response to desmopressin. Am J Hypert 12(2 Pt 1): 188-193.

31. Haberichter SL, Shi Q, Montgomery RR (2006) Regulated release of VWF and factor 8 and its biologic implications. Pediatr Blood Cancer 46(5): 547-553.

32. Takeda T, Takeda S, Kitano H, Okada T, Kakigi A (2000) Endolymphatic hydrops induced by chronic administration of vasopressin. Hear Res 140(1-2): 1-6.

33. Ianucci NB, Ripoli GV, Garona J, Osvaldo Cascone, Graciela N Ciccia, et al. (2011) Antiproleferative effect of 1-demino-8-D-arginine vasopressin analogs on human breast cancer cells. Future Med Chem 3(16): 1987 1993.

34. Noh JM, Park W, Hub SJ, Cho EY, Choi YL, et al. (2009) Correlation between tumor volume response to radiotherapy and expression of biolog- ical markers in patients with cervical squamous cell carcinoma. J Gyncol Oncol 20(4): 215-220

35. Pegueux C, Breton C, Hagelstein M, Geenen V, Legros JJ (2005) Oxytocin receptor pattern of expression in primary lung cancer and in normal human lung. Lung Cancer 50(2): 177-188.

36. Wang F, Tang K, Yen Y, Ho DM, Yang AH, et al. (2012) Plasma corticotrophin response to desmopressin in patients with Cushing's disease correlates with the expression of vasopressin receptor 2 , but not with that of vasoreceptor 1 or 3 in their pituitary tumors. Clin Endocrinol (Oxf) 76(2): 253-263.

37. Regard JB, Sato IT, Coughlin SR (2008) Anatomic profiling of G protein-coupled receptor expression. Cell 135(3): 561-571.

38. Lin J, Sharma N, Zheng W, Ji H, Tam H, et al. (2011) Sex differences in vasopressin V2 receptor expression and vasopressin-induced antidiuresis. Am J Physiol Renal Physiol 300(2): F433-F440.

39. Juul KV, Klein BM, Norgaard JP (2013) Long-term durability of the response to desmopressin in female and male nocturia patients. Neurourol Urodyn 32(4): 363-370.

40. Pinto CS, Rolf GA, Nivens E, White C, Wallace DP (2012) Calmodulin-sensitive adenylcyclases mediate AVP-dependent cAMP production and Cl-secretion by human autosomal dominant polycystic kidney cells. Am J Physiol Renal Physiol 303(10): F1412-F1424.

41. Bichet DG (2012) Genetics and diagnosis of central diabetes insipidus. Ann Endocrinol 73(2): 117-127.

42. Bichet DG ( 2009) V2R mutations and nephrogenic diabetes insipidus. Progr Mol Biol Transl Sci 89: 15-29.

43. Shepsholovic D, Leibovitch C, Klein A, Zoldan S, Milo G, et al. (2015) The syndrome of inappropriate antidiuretic hormone secretion: distribution and characterization according to etiologies. Eur J Intern Med 26(10): 819-824.

44. Van Meerbeeck JP, Feneli DA, DeRuysscher DK (2011) Small cell lung cancer. Lancet 378(9804): 1741-1755.

45. Salahadeen AK, Ali H, George M, Lahoti A, Palla S (2014) Tolvaptan in hospitalized cancer patients with hyponatremia: a double-blind, randomized, placebo-controlled clinical trial on efficacy and safety. Cancer 120(5): 744-751.

46. Gralla RJ, Ahmad F, Blais JD, Chiodo J, Zhou W, et al. (2017) Tolvaptan use in cancer patients with hyponatremia due to the syndrome of inappropriate antidiuretic hormone: a post hoc analysis of the SALT-1 and SALT-2 trials. Cancer Med 6(4): 723-729.

47. Schrier RW, Gross P, Gheoghiade M, Berl T, Verbalis JG, et al. (2006) Tolvaptan, a selective oral vasopressin V2-receptor antagonist, for hyponatremia. N Engl J Med 355(20): 2099-2112.

48. Berl T, Quitnat Pelletier F, Verbalis JG, Schrier RW, Bichet DG, et al. (2010) Oral tolvaptan is safe and effective in chronic hyponatremia. J Am Soc Nephrol 21(4): 705-712.

49. Zeltser D, Rosansky S, Van Rensburg H, Verbalis JG, Smith N, et al. (2007) Assessment of the efficacy and safety of intravenous conivaptan in euvolemic and hypervolemic hyponatremia. Am J Nephrol 27(5): 447-457.

50. Rondon Berrios H, Berl T (2017) Vasopressin Receptor Antagonists in Hypernatremia:Uses and Misuses. Front Med 4: 141.

51. Rosen Zvi B, Yahav D, Gheorghiade M, Korzets A, Leibovici L, et al. (2010) Vasopressin receptor antagonists for the treatment of hyponatremia: systematic review and meta-analysis. Am J Kidney Dis 56(2): 325-337.

52. Jaber BL, Almarzougi L, Borgi L, Seabra VF, Balk EM, et al. (2011) Shortterm efficacy and safety of vasopressin receptor antagonists for treatment of hyponatremia. Am J Med 124(10): 977. 
53. Zhang X, Zhao M, Du W, Zu D, Sun Y, et al. (2016) Efficacy and safety of vasopressin receptor antagonists for euvolemic or hypervolemic hyponatremia: a mete-analysis. Medicine (Baltimore) 95(15): e3310.

54. Li B, Fang D, Qian C, Feng H, Wang Y (2017) The efficacy and safety of tolvaptan in patients with hyponatremia; a meta-analysis of randomized controlled trials. Clin Drug Investig 37(4): 327-342.

55. Bhandari S, Peri A, Cranston L, McCool R, Shaw A, et al. (2017) A systematic review of known interventions for the treatment of chronic nonhypovolemic hypotonic hyponatremia and a meta-analysis of the vaptans. Clin Endocrinol (Oxf) 86(6): 761-771.

56. Verbalis JG, Greenberg A, Burst V, Haymann JP, Johannsson G, et al. (2016) Diagnosing and treating the syndrome of inappropriate antidiuretic hormone secretion. Am J Med 124(5): 537.

57. Burst V, Grundmann F, Kubachi T, Greenberg A, Rudolf D, et al. (2017) Euvolemic hyponatremia in cancer patients.Report of the hyponatremia registry: an observational multicenter international study. Support Care Cancer 25(7): 2275-2283.

58. Palmer BF (2003) Hyponatremia in patients with central nervous system disease:SIADH versus CSWS. Trends Endocrinol Metab 14(4): 182187.

59. Hannon MJ, Behan LA, O Brien MM, Tormey W, Ball SG, et al. (2014) Hyponatremia following mild to moderate subarachnoid hemorrhage is due to SIAD and glucocorticoid deficiency and not cerebral salt wasting. J Clin Endocrinol Metab 99(1): 291-298.

60. Verbalis JG (2014) Hyponatremia with intracranial disease not often cerebral salt wasting. J Clin Endocrinol Metab 99(1): 59-62.

61. Torres VE, Chapman AR, Devuyst O, Gansevoort RT, Grantham JJ, et al (2012) Tolvaptan in patients with autosomal dominant polycystic kidney disease. N Engl J Med 367(25): 2407-2418.

62. Watkins PB, Lewis JH, Kaplowitz N, Alpers DH, Blais JD, et al. (2015) Clinical pattern of tolvaptan-associated liver injury in subjects with autosomal dominant polycystic kidney disease: analysis of clinical trials database. Drug Saf 38(11): 1103-1113.

63. US Food and Drug Administration (2013) FDA Drug Safety Communication: FDA Limits Duration and Usage of Samsca (Tolvaptan) due to Possible Liver Injury Leading to Organ Transplant or Death.

64. Lehrich RW, Greenberg A (2012) Hyponatremia and the use of vasopressin receptor antagonists in critically ill patients. J Intensive Care Med 27(4): 207-218.

65. Wiley CJ, Blais JD, Hall AK, Krasa HB, Makin AJ, et al. (2017) Prevalence of autsomal dominant polycystic kidney disease in the European Union. Nephrol Dial Transplant 32(8): 1356-1363.

66. Torres VE, Harris PC, Pirson Y (2007) Autosomal dominant polycystic kidney disease. Lancet 369(9569): 1287-1301.

67. Spithoven EM, Kramer A, Meyer E, Orskov B, Wanner C, et al. (2014) Analysis of data from the ERA-EDTA registry indicates that conventional treatments for chronic kidney disease do not reduce the need for renal replacement therapy in autosomal dominant polycystic kidney disease. Kidney Int 86(6): 1244-1252.

68. Chapman AB, Devuyst O, Eckhardt KU, Gansevoort RT, Harris T, et al. (2015) Autosomal dominant polycystic kidney disease (ADPKD):executive summary from a kidney disease: improving global outcomes (KDIG0) controversies conference. Kidney Int 88(1): 17-27.

69. Schrier RW, Abebe KZ, Perrane RD, Torreset VE, Braun WE, et al. (2014) Blood pressure in early autosomal dominant polycystic kidney disease. N Engl J Med 371: 2255-2266.

70. Torres VE, Chapman AB, Devuyst O, Gansevoort RT, Perrone RD, et al. (2017) Multicenter open-label, extension trial to evaluate the long-term efficacy and safety of early versus delayed treatment with tolvaptan in autosmal dominant polycystic kidney disease: The TEMPO 4:4 Trial. Nephrol Dial Transplant 32(7): 1262.

71. Kielstein R, Sass HM (2002) Genetics in kidney disease:how much do we want to know? Am J Kidney Dis 39(3): 637-652.

72. Gansevoort RT, Arici M, Benzing T, Birn H, Capasso G, et al. (2016) Recommendations for the use of tolvaptan in autosomal dominant polycystic kidney disease: a position statement on behalf of the ERA-EDTA Working Group on Inherited Kidney Disorders and European Renal Best Practice. Nephrol Dial Transplant 31(3): 337-348.

73. Verbalis JG, Ellison H, Hobart M, Krasa H, Ouyang J, et al. (2016) Tolvaptan and neurocognitive function in mild to moderate chronic hyponatremia: a randomized trial (INSIGHT). Am J Kidney Dis 67(6): 893-901.

74. Georghiade M, Gattis WA, Oconnor CM, Adams KF, Elkayam U, et al. (2004) Effects of tolvaptan,a vasopressor antagonist, in patients hospitalized with worsening heart failure: a randomized controlled trial. JAMA 291(16): 1963-1971.

75. Rossi J, Bayram M, Udelson JE, Lloyd Jones D, Adams KF, et al. (2007) Improvement in hyponatremia during hospitalization for worsening heart failure is associated with improved outcomes: insights from the acute and chronic therapeutic impact of a vasopressin antagonist in heart failure (Activ in CHF) trial. Acute Card Care 9(2): 82-86.

76. Konstam MA, Georghiade M, Burnett JC, Grinfeld L, Maggioni AP, et al. (2007) Effects of oral tolvaptan in patients hospitalized for worsening heart failure: the EVEREST trial. JAMA 297(12): 1319-1331.

77. Hauptman PJ, Burnett J, Georghiade M, Grinfeld L, Konstam MA, et al. (2013) Clinical course of patients with hyponatremia and decompensated systolic heart failure and the effect of vasopressin receptor antagonism with tolvaptan. J Card Fail 19(6): 390-397.

78. Amin AH, Ordenhendahl JD, Harmn AL, Kamat SA, Stellhorn RA, et al. (2018) Utilization and budget impact of tolvaptan in the inpatient setting among patients with heart failure and hyponatremia. Curr Med Res Opin 34(3): 559-566

79. Barnawi R, Attar RZ, Alfaer SS, Safdar OY (2018) Is the light at the end of the tunnel nigh? A revuew of ADPKD focusing on the burden of disease and tolvaptan as a new treatment. Int J Nephrol Renovasc Dis 11: 53-67.

80. Erickson KF, Cherlow GM, Goldhaber Fiebert JD (2013) Cost-effectiveness of tolvaptan in autosomal dominant polycystic kidney disease. Ann Int Med 159(6): 382-389.

81. Nee R, Yuan CM, Abbott KC (2014) Isn't ironic? Cost effectiveness and willingness to pay for tolvaptan in the prevention of kidney failure in autosomal dominant polycystic kidney disease. Am J Kidney Dis 63(4): 552-554.

82. Dasta JF, Chiong JR, Christian R, Lin J (2012) Evaluation of costs associated with tolvaptan-mediated hospital length of stay reduction among U.S. patients with the syndrome of innappropriate antidiuretic hormone secretion,base don SALT-1 and SALT-2 trials. Hosp Pract (1995) 40(1): 7-14.

83. Cyr PL, Slawasky KA, Olchanski N, Krasa HB, Goss TF, et al. (2011) Effect of serum sodium concentration and tolvaptan treatment on length of hospitalization in patients with heart failure. Am J Health Syst Pharm 68(4): 328-333.

84. Lee MY, Kang HJ, Park SY, Kim HL, Han E, et al. (2014) Cost-effectiveness of tolvaptan for euvolemic or hypervolemic hyponatremia. Clin Ther 36(9): 1183-1194.

85. Jamokeeah C, Robinson P, Oreilly K, Lundberg J, Gisby M, et al. (2016) Cost-effectiveness of tolvaptan for the treatment of hyponatremia secondary to syndrome of inappropriate antidiuretic hormone secretion in Sweden. BMC Endocr Disord 16(1): 22. 
Creative Commons Attribution 4.0 International License

For possible submissions Click Here

Submit Article
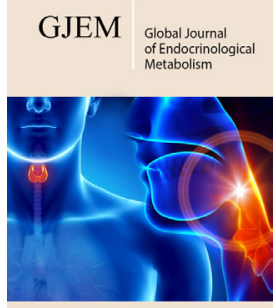

Global Journal of Endocrinological Metabolism

\section{Benefits of Publishing with us}

- High-level peer review and editorial services

- Freely accessible online immediately upon publication

- Authors retain the copyright to their work

- Licensing it under a Creative Commons license

- Visibility through different online platforms 